UDC 347.73:339.186

LBC 67.402 .02

\title{
THE SYSTEM OF FINANCIAL CONTROL IN GOVERNMENT AND MUNICIPAL PROCUREMENT
}

\author{
Imadi Ali Vugar oglu Huseynli \\ Volgograd State University, Volgograd, Russian Federation
}

\begin{abstract}
Introduction: keeping a system of financial control became a novel contract system in the sphere of public procurement, established by the Federal law of 05.04.2013 No. 44-FZ "On contract system in procurement of goods, works, services for state and municipal needs". Methods: in order to improve the efficiency of the practical application of legal norms regulating the control over the implementation of state and municipal procurement, in addition to exercising administrative controls, special attention should be paid to financial control, namely the spending budget because the end result for financial support of public procurement is possible only if the legitimate and efficient use of funds of the respective budgets. Results: this article is devoted to questions of carrying out of financial control, which is part of the mechanism of General financial control, the implementation of state and municipal procurement. Conclusions: the results of the conducted research it is established that in the Russian Federation for state and municipal needs spent a significant amount of public financial resources. The main objective of satisfying the above requirements is to increase the effective use of data resources and the transition to a mode of rigid economy of budgetary funds. To achieve this, the state uses a variety of techniques and tools of financial activities. One of them was the contract system in procurement of goods, works, services for state and municipal needs. The practice of application of the contract system has revealed certain weaknesses in the implementation of state (municipal) procurement, in particular: a well-established system of control over observance of legislation on the contract system and financial control over the effective use of public funds spent through this system. The solution to these problems is impossible without further development of financial-legal regulation of relations in the field of contract system in the procurement area, in particular the relationship to improve the funding mechanism, procurement, and control, primarily financial, for their implementation.
\end{abstract}

Key words: contract system, customer, state and municipal procurement, the ways of placing of the state order, financial control, budgetary funds.

УДК 347.73:339.186

ББК 67.402 .02

\section{СИСТЕМНЫЙ ФИНАНСОВЫЙ КОНТРОЛЬ ПРИ ОСУЩЕСТВЛЕНИИ ГОСУДАРСТВЕННЫХ И МУНИЦИПАЛЬНЫХ ЗАКУПОК}

\author{
Имади Али Вугар оглы Гусейнли \\ Волгоградский государственный университет, г. Волгоград, Российская Федерация
}

Введение: ведение системного финансового контроля стало новеллой контрактной системы в сфере
закупок, установленной Федеральным законом от 05.04.2013 г. № 44-Ф3 «О контрактной системе в сфере
закупок товаров, работ, услуг для обеспечения государственных и муниципальных нужд». Методы: в целях
повышения эффективности практического применения правовых норм, регулирующих контроль за осуще-
ствлением государственных и муниципальных закупок, помимо осуществления административного контро-
ля особое внимание необходимо уделить финансовому контролю, а именно расходованию бюджетных средств,
поскольку конечный результат по финансовому обеспечению государственных закупок возможен только
при законном и эффективном использовании денежных средств соответствующих бюджетов. Результаты:
данная статья посвящена вопросам проведения финансового контроля, являющегося элементом механизма
общего финансового контроля, при осуществлении государственных и муниципальных закупок. Выводы: в
итоге проведенного исследования установлено, что в Российской Федерации для обеспечения государствен- 
ных и муниципальных нужд расходуется значительный объем публичных финансовых ресурсов. Основной задачей удовлетворения вышеобозначенных потребностей остается повышение эффективности использования данных ресурсов и переход к режиму жесткой экономии бюджетных средств. Для достижения этого государство использует различные приемы и инструменты финансовой деятельности. Одним из них стала контрактная система в сфере закупок товаров, работ и услуг для обеспечения государственных и муниципальных нужд. Практика применения контрактной системы открыла определенные недостатки в реализации государственных (муниципальных) закупок, в частности неотлаженность системы контроля за соблюдением законодательства о контрактной системе и финансового контроля за эффективностью использования публичных денежных фондов, расходуемых через данную систему. Решение данных проблем невозможно без дальнейшего развития финансово-правового регулирования отношений в области контрактной системы в сфере закупок, в частности отношений по усовершенствованию механизма финансирования, осуществления закупок, а также контроля (прежде всего финансового) за их исполнением.

Ключевые слова: контрактная система, заказчик, государственные и муниципальные закупки, способы размещения государственного заказа, финансовый контроль, бюджетные средства.

\section{Введение}

Процесс обеспечения государственных и муниципальных нужд всегда подразумевает под собой целевое расходование бюджетных средств, и, следовательно, требует надлежащего контроля. Следует отметить, что государственные (муниципальные) закупки представляют собой одну из крупнейших расходных статей бюджетов всех уровней, что создает благоприятную среду для развития коррупционных явлений и нецелевого использования финансовых ресурсов государства. В этой связи контроль в исследуемой сфере приобретает особое значение.

До принятия Федерального закона от 05.04.2013 г. № 44-Ф3 «О контрактной системе в сфере закупок товаров, работ, услуг для обеспечения государственных и муниципальных нужд» (далее - Закон № 44-Ф3) специальное законодательство РФ о государственных (муниципальных) закупках не содержало норм об обязательности, форме и порядке проведения финансового контроля в исследуемой сфере. Статья 17 утратившего силу Федерального закона от 21.07.2005 г. № 94-Ф3 «О размещении заказов на поставки товаров, выполнение работ, оказание услуг для государственных и муниципальных нужд» содержала лишь норму о проведении плановых и внеплановых мероприятий по контролю над исполнением законодательства РФ. Однако на практике указанная правовая норма действовала сугубо неэффективно. А.А. Строганов видит причину подобной неэффективности в отсутствии на тот момент систематизирован- ного и последовательного контроля всей процедуры размещения заказа, начиная от этапа планирования, и до момента исполнения контрактных обязательств [5, с. 48]. По мнению Е.А. Малыхиной, проблема Федерального закона № 94-Ф3 заключалась также в отсутствии надлежащей регламентации взаимодействия контролирующих органов различных уровней, поскольку функции финансового контроля выполняли как территориальные управления Федеральной антимонопольной службы, так и органы исполнительной власти субъектов РФ [2, с. 249]. В процессе разработки Федерального закона № 44-Ф3 законодателем была осознана острая необходимость во введении качественно новой формы системного финансового контроля, объединяющего в себе мероприятия по мониторингу процесса закупок на всех его стадиях, аудиту и общественному контролю. Основная цель такой формы контроля заключалась в противодействии нарастающей коррупции среди должностных лиц, имеющих непосредственное отношение к процессу государственных (муниципальных) закупок и расходованию бюджетных средств.

\section{Финансовый контроль: понятие и виды}

В настоящее время Закон № 44-ФЗ включает две главы, посвященные мероприятиям по финансовому контролю в исследуемой сфеpe: мониторингу и аудиту в сфере закупок, а также контролю в сфере закупок. В научной литературе виды финансового контроля в сфере закупок принято классифицировать в зави- 
симости от объекта контроля. Так, по данному основанию Е.А. Малыхина выделяет следующие виды финансового контроля, проводимые от лица государственных (муниципальных) органов:

- за соблюдением законодательства РФ и иных нормативно-правовых актов о контрактной системе в исследуемой сфере;

- за целевым и эффективным расходованием бюджетных средств;

- ведомственный контроль;

- проведение мониторинга закупок;

- проведение аудита в сфере закупок;

- контроль, осуществляемый заказчиком (государственным или муниципальным органом).

Также выделяется общественный контроль, целью которого является соблюдение всеми участниками государственных (муниципальных) закупок требований законодательства РФ. Однако поскольку мониторинг и аудит в сфере закупок выделены законодателем в отдельную главу Закона № 44-Ф3, представляется, что более правильным будет рассмотреть их отдельно.

Объектом контрольных мероприятий является деятельность всех участников сферы закупок, в том числе заказчиков, управляющих, различных комиссий, специализированных организаций и непосредственных операторов электронных площадок ЕИС.

По мнению К.Б. Маркелова, финансовому контролю подлежат все этапы государственных и муниципальных закупок: определение потребности в товаре, услуге, работе; формирование заказа; размещение заказа; исполнение государственного и муниципального контракта; анализ результатов размещения заказа. Автор делает вывод о том, что финансовый контроль необходимо рассматривать как в широком смысле, а именно в системе общего государственного финансового контроля, так и в узком, как финансовый контроль за расходованием бюджетных средств при осуществлении государственных и муниципальных закупок [3, с. 45].

Прежде чем рассуждать о видах финансового контроля в исследуемой сфере, следует дать определение указанному понятию. Действующее законодательство РФ не содержит легального определения понятия «финан- совый контроль». БК РФ определяет лишь цель его проведения, которая заключается во всестороннем обеспечении соблюдения законодательства РФ. В научной литературе также не существует единого понимания термина «финансовый контроль». Так, Н.И. Химичева понимает под ним «соблюдение законности и целесообразности действий в области образования, распределения и использования государственных, муниципальных и иных денежных ресурсов государственного характера» [10, с. 139]. М.М. Прошунин предлагает понимать под финансовым контролем совокупность принимаемых уполномоченным органом мер по контролю за операциями с денежными средствами или иным имуществом на основании информации, представляемой ему организациями, осуществляющими такие операции, а также по проверке этой информации в соответствии с законодательством РФ [8, с. 24].

Мы же полагаем возможным согласиться с точкой зрения Е.Ю. Грачевой, по мнению которой финансовый контроль представляет собой «санкционированную нормативно-правовыми актами деятельность уполномоченных государственных, муниципальных, общественных органов и организаций, иных субъектов по соблюдению своевременности и точности финансового планирования, обоснованности и полноты поступления доходов в соответствующие фонды денежных средств, правильности и эффективности их использования в целях достижения стоящих перед государством задач» [6, с. 36].

Как определяет Е.Ю. Грачева, «отличие надзора от контроля в том, что, во-первых, органы надзора и поднадзорные органы не находятся в отношениях подчиненности (например, государственные инспекции, прокуратура) и, во-вторых, надзорные органы выявляют у поднадзорных только нарушения законности, но не нарушения целесообразности» $[11$, с. 120]. Между тем, по справедливому замечанию указанного автора, «несмотря на качественное отличие контроля от надзора, среди современных точек зрения на сущность финансового контроля отсутствует четкое разделение на контроль и надзор в финансовой сфере. Понятие “финансовый контроль" зачастую используется как обобщающий термин, 
включающий как мероприятия по контролю, так и различные надзорные меры».

Рассмотрим более подробно виды контроля в сфере государственных (муниципальных) закупок. В соответствии со ст. 99 Закона № 44-Ф3, контроль в сфере закупок осуществляется со стороны перечисленных органов исполнительной власти РФ, субъектов РФ, местного самоуправления. Однако Закон № 44-Ф3 не определяет область контроля вышеуказанных субъектов, а лишь указывает на наличие у них полномочий на проведение мероприятий контроля путем плановых и внеплановых проверок. Объем полномочий органов исполнительной власти в сфере государственных (муниципальных) закупок конкретизируется в подзаконных нормативных актах, принимаемых в соответствии с Законом № 44-ФЗ. Так, согласно Постановлению Правительства РФ от 26.08.2013 г. № 728, федеральным органом исполнительной власти, уполномоченным на произведение контроля в сфере закупок, является Федеральная антимонопольная служба РФ (ФАС) [4]. В настоящее время ФАС России проводит огромную работу по контролю за исполнением всеми участниками процесса государственных (муниципальных) закупок финансового законодательства РФ. Непосредственные полномочия службы и порядок их реализации подробно урегулирован отдельным Приказом ФАС России от 11.02.2014 г. № 75/14 [7].

\section{Порядок осуществления контроля}

На современном этапе развития института контрактной системы закупок товаров, работ и услуг мероприятия финансового контроля проводятся на каждом этапе его работы, в том числе и в процессе формирования объема государственных (муниципальных) нужд, непосредственного их финансирования путем бюджетных финансовых ресурсов, производства закупок товаров, работ или услуг. Финансовый контроль, являясь деятельностью уполномоченных государственных и муниципальных органов, базируется как на общеправовых принципах, так и на принципах, присущих исключительно этому виду деятельности. Среди общеправовых принципов можно выделить законность, открытость, гласность, плановость и федерализм. Закон № 44-Ф3 не указывает на какие-либо основополагающие принципы осуществления финансового контроля в сфере закупок. Однако указанные принципы нашли свое отражение в Федеральном законе от 05.04.2013 г. № 41-Ф3 «О Счетной палате Российской Федерации», согласно которому указанный исполнительный орган осуществляет внешний аудит, основываясь на принципах законности, эффективности, объективности и независимости.

В соответствии со ст. 99 закона № 44-Ф3 контроль осуществляется в отношении следующих объектов:

1) информации об объеме финансового обеспечения закупки;

2) информации об идентификационных кодах (ID) закупки, содержащихся в подлежащих размещению в ЕИС:

- планах закупок;

- планах-графиках закупок;

- извещениях;

- протоколах;

- сведениях о контрактах.

Правила осуществления такого контроля установлены Постановлением Правительства РФ от 12.12.2015 г. № 1367 «О порядке осуществления контроля, предусмотренного частью 5 ст. 99 Федерального закона "О контрактной системе в сфере закупок товаров, работ, услуг для обеспечения государственных и муниципальных нужд”, вступившим в силу 1 марта 2017 г., с изменениями и дополнениями от 20 марта 2017 г.» (далее - Правила осуществления контроля) [5].

Контроль в отношении указанных документов и информации (объекты контроля) проводится контрольными органами при их направлении субъектами контроля для размещения в Единой информационной системе в сфере закупок (ЕИС).

Если в соответствии с требованиями Правил осуществления контроля объекты контроля не подлежат размещению в ЕИС, контроль в отношении данных объектов будет осуществляться путем направления с соблюдением требований законодательства РФ о защите государственной тайны (если такие объекты контроля содержат сведения, составляющие государственную тайну) на согласование в орган контроля: 
- утвержденных в установленном порядке планов закупок и планов-графиков закупок, в том числе изменений, внесенных в них;

- информации об идентификационном коде закупки и об объеме финансового обеспечения закупки, утвержденной и доведенной до заказчика в установленном порядке, включенной в приглашения принять участие в определении поставщиков (подрядчиков, исполнителей), документацию о закупках, протоколы определения поставщиков (подрядчиков, исполнителей) и проекты контрактов, до направления соответствующих объектов контроля участникам закупок;

- данных о контракте при их представлении в установленном порядке для включения в реестр контрактов, содержащих сведения, составляющие государственную тайну.

Порядок осуществления финансового контроля установлен Правилами осуществления контроля, в частности в п. 13 устанавливается следующее. В ходе проводимых мероприятий контрольные органы осуществляют проверку информации об объеме финансового обеспечения, включенного в планы закупок, и информации:

- о лимитах бюджетных обязательств на закупку товаров, работ и услуг на соответствующий финансовый год и плановый период;

- о показателях выплат на закупку товаров, работ и услуг, осуществляемых в соответствии с законом № 44-Ф3, и включенных в планы финансово-хозяйственной деятельности государственных (муниципальных) бюджетных и автономных учреждений;

- об объемах финансового обеспечения осуществления капитальных вложений, предоставляемых государственным (муниципальным) унитарным предприятиям в соответствии со ст. 78.2 БК РФ.

В процессе осуществления контроля, согласно п. 13 Правил осуществления контроля, исследуются: начальная максимальная цена контракта; возможность ее искусственного завышения; несоответствие цены контракта и идентификационного кода закупки; превышения начальной (максимальной) цены контракта, содержащейся в протоколе определения поставщика; аналогичных цен, содержащихся в документации о закупке, и пр.
В случае выявления фактов нарушений, контрольные органы направляют субъектам контроля протокол с указанием всех недочетов, при этом объекты контроля не размещаются в информационной системе до устранения нарушения и прохождения повторного контроля.

Кроме этого, формируется отметка о несоответствии контролируемой информации, включенной в объект контроля, не подлежащий размещению в информационной системе, и направляется протокол с указанием выявленных несоответствий в течение трех рабочих дней со дня направления объекта контроля на согласование в орган контроля.

Орган контроля в течение трех часов с момента формирования результатов контроля обязан уведомить в электронной форме субъект контроля о результатах проверки.

Законодатель, перечисляя в главе 5 Закона № 44-Ф3 виды контроля, возможного к применению в сфере закупок, не указывает на методы практического осуществления данного контроля. В этой связи представляется необходимым обратиться к нормам бюджетного законодательства РФ. БК РФ в ст. 267.1 выделяет следующие методы финансового контроля: обследование, проверка, санкционирование финансовых операций, ревизия. Применительно к отношениям в сфере закупки товаров, работ и услуг для государственных и муниципальных нужд следует выделить два дополнительных метода, указанные в главе 4 Закона № 44-Ф3 - мониторинг и аудит.

Определяя круг субъектов, осуществляющих финансовый контроль в сфере закупок, необходимо отметить полномочия различных ведомств в отношении заказчиков, подконтрольных им. В соответствии со ст. 100 Закона № 44-Ф3, мероприятия финансового контроля, наряду с уполномоченными исполнительными органами власти, вправе производить также государственная корпорация по атомной энергии «Росатом», Государственная корпорация по космической деятельности «Роскосмос», органы управления государственными внебюджетными фондами, муниципальные органы. Однако указанные субъекты вправе реализовать полномочия по финансовому контролю исключительно в отношении подконтрольных им заказчиков. Такая форма 
финансового контроля получила название ведомственного контроля, и является новшеством для российского законодательства в сфере государственных (муниципальных) закупок. Субъекты ведомственного контроля действуют в качестве главных распорядителей бюджетных средств, следовательно, им же принадлежит право на разработку и принятия регламентов осуществления мероприятий ведомственного контроля над заказчиками, находящимися в их подведомственности.

В ст. 101 Закона № 44-Ф3 законодатель предусматривает особую форму финансового контроля, при которой контрольные мероприятия производятся непосредственно самим заказчиком. Интересным является тот факт, что заказчик наделяется не правом осуществления контроля над сферой закупок, а обязанностью производить соответствующую работу. По аналогии с предыдущими положениями закона № 44-Ф3, ст. 101 не содержит каких-либо сведений об объеме полномочий заказчиков в исследуемой сфере и порядке их реализации. Следовательно, право разработки регламента осуществления финансового контроля в данном случае также принадлежит заказчикам.

Все вышеперечисленные формы финансового контроля объединяет наличие в качестве субъекта контроля государственного или муниципального органа, ведомства. Форма финансового контроля в сфере закупок, закрепленная в ст. 102 Федерального закона № 44-Ф3 отличается именно субъектным составом. Впервые законодателем в исследуемой сфере легально закреплена возможность осуществления финансового контроля со стороны граждан, общественных организаций и объединений юридических лиц. Следует отметить, что предыдущий Федеральный закон, регулирующий сферу государственных (муниципальных) закупок, не содержал подобной правовой нормы. В этой связи стоит согласиться с мнением Е.А. Малыхиной, которая называет появление ст. 102 важным преимуществом над предшествующим законодательством [6, с. 35].

С момента вступления в законную силу Закона № 44-Ф3 граждане, общественные объединения и объединения юридических лиц вправе осуществлять общественный контроль за соблюдением законодательства РФ о контрактной системе в сфере закупок, а органы государственной власти и органы местного самоуправления обязаны обеспечивать возможность осуществления такого контроля. Цель общественного контроля в сфере закупок, по мнению законодателя, состоит в практической реализации принципов единой контрактной системы в сфере закупок, содействии в ее развитии, а также профилактики и выявлении нарушений законодательства РФ в исследуемой сфере. Помимо вышеуказанных функций, с принятием Закона № 44-Ф3 граждане и общественные организации получили право проведения мониторинга в сфере обеспечения государственных и муниципальных нужд. В научной литературе авторы признают исключительную значимость появления института общественного контроля. Так, М.А. Лапина видит в нем мощный инструмент для выявления коррупционных преступлений в сфере закупок и борьбы с ними [1, с. 26].

\section{Выводы}

В заключение следует отметить, что введение системного финансового контроля стало новеллой контрактной системы в сфере закупок, установленной Законом № 44-Ф3. Выделяются следующие виды финансового контроля: 1) за соблюдением законодательства РФ и иных нормативно-правовых актов о контрактной системе в исследуемой сфере; 2) за целевым и эффективным расходованием бюджетных средств; 3) ведомственный контроль; 4) контроль, осуществляемый заказчиком (государственным или муниципальным органом); 5) общественный контроль. Все вышеперечисленные виды финансового контроля (кроме общественного) объединяет наличие в качестве субъекта контроля государственного или муниципального органа, ведомства. В то же время общественный контроль является важным механизмом, позволяющим дополнительно выявлять факты коррупции в ходе осуществления государственных (муниципальных) закупок. Методами финансового контроля выступают обследование, проверка, санкционирование финансовых операций, ревизия. 


\section{СПИСОК ЛИТЕРАТУРЫ}

1. Лапина, М. А. Общественный финансовый контроль как показатель развития гражданского общества / М. А. Лапина, А. В. Лапин // Финансовое право. - 2013. - № 4. - С. 25-33.

2. Малыхина, Е. А. Особенности финансовоправового регулирования отношений, возникающих в процессе реализации контрактной системы в сфере закупок товаров, работ, услуг для обеспечения государственных и муниципальных нужд/Е. А. Малыхина // Вестник СГЮА. - 2014. - № 2. - С. 249-253.

3. Маркелов, К. Б. Государственные и муниципальные закупки как институт бюджетного права : дис. ... канд. юрид. наук / Маркелов Кирилл Борисович. - М., 2012. $-166 \mathrm{c.}$

4. Постановление Правительства РФ «Об определении полномочий федеральных органов исполнительной власти в сфере закупок товаров, работ, услуг для обеспечения государственных и муниципальных нужд и о внесении изменений в некоторые акты Правительства Российской Федерации» от 26 авг. 2013 г. № 728 (ред. от 25 дек. 2014 г.) // Собрание законодательства РФ. - 2013. - № 35. Ст. 4514.

5. Постановление Правительства РФ «О порядке осуществления контроля, предусмотренного частью 5 статьи 99 Федерального закона “О контрактной системе в сфере закупок товаров, работ, услуг для обеспечения государственных и муниципальных нужд”» от 12 дек. 2015 г. № 1367 // Собрание законодательства РФ. - 2015. - № 52 (Ч. І). - Ст. 7602.

6. Правовое регулирование финансового контроля в Российской Федерации: проблемы и перспективы : монография / Л. Л. Арзуманова, О.В.Болтинова, О. Ю. Бубнова и др. ; отв. ред. Е. Ю. Грачева. - М. : Норма : ИНФРА-М, 2013. - 384 с.

7. Приказ ФАС России «Об осуществлении Федеральной антимонопольной службой и территориальными органами Федеральной антимонопольной службы полномочий по контролю в сфере закупок товаров, работ, услуг для обеспечения государственных и муниципальных нужд в связи с вступлением в силу Федерального закона от 5 апр. 2013 г. № 44-Ф3 “О контрактной системе в сфере закупок товаров, работ, услуг для обеспечения государственных и муниципальных нужд"» от 11 февр. 2014 г. № 75/14. - Доступ из справ.-правовой системы «КонсультантПлюс».

8. Прошунин, М. М. К вопросу о соотношении финансового мониторинга и финансового контроля / М. М. Прошунин // Финансовое право. 2010. - № 10. - C. 21-24.

9. Строганов, А. А. Госзаказ и контроль за его размещением / А. А. Строганов. - М. : Юриспруденция, 2010.-208 c.
10. Финансовое право : учебник / отв. ред. Н. И. Химичева. -5 -е изд., перераб. и доп. - М. : Норма : ИНФРА-М, 2012.-752 с.

11. Финансовое право : учебник / под ред. Е. И. Грачевой. - М. : Проспект, 2015. - 587 с.

\section{REFERENCES}

1. Lapina M.A., Lapin A.V. Obshchestvennyy finansovyy kontrol kak pokazatel razvitiya grazhdanskogo obshchestva [Public Financial Control as an Indicator of Civil Society Development]. Finansovoe pravo, 2013, no. 4, pp. 25-33.

2. Malykhina E.A. Osobennosti finansovopravovogo regulirovaniya otnosheniy, voznikayushchikh $\mathrm{v}$ protsesse realizatsii kontraktnoy sistemy $\mathrm{v}$ sfere zakupok tovarov, rabot, uslug dlya obespecheniya gosudarstvennykh i munitsipalnykh nuzhd [Financial and Legal Regulation of Relations Arising in the Process of Implementing a Contract System in the System of Procurement of Goods, Works, Services to Ensure State and Municipal Needs]. Vestnik SGYuA, 2014, no. 2, pp. 249-253.

3. Markelov K.B. Gosudarstvennye $i$ munitsipalnye zakupki kak institut byudzhetnogo prava: dis. ... kand. yurid. nauk [State and Local Procurement as the Budget Law Institute. Cand. jurid. sci. diss.]. Moscow, 2012. 166 p.

4. Postanovlenie Pravitelstva RF «Ob opredelenii polnomochiy federalnykh organov ispolnitelnoy vlasti $\mathrm{v}$ sfere zakupok tovarov, rabot, uslug dlya obespecheniya gosudarstvennykh i munitsipalnykh nuzhd i o vnesenii izmeneniy v nekotorye akty Pravitelstva Rossiyskoy Federatsii» ot 26 avg. 2013 g. № 728 (red. ot 25 dek. 2014 g.) [Decree of the Government of the Russian Federation "On Determining the Powers of Federal Executive Bodies in the Sphere of Procurement of Goods, Works and Services to Ensure State and Municipal Needs and on Amending Certain Acts of the Government of the Russian Federation" of August 26, 2013 no. 728 (as amended on December 25, 2014)]. Sobranie zakonodatelstva RF, 2013, no. 35, art. 4514.

5. Postanovlenie Pravitelstva $\mathrm{RF} \ll \mathrm{O}$ poryadke osushchestvleniya kontrolya, predusmotrennogo chastyu 5 statyi 99 Federalnogo zakona "O kontraktnoy sisteme v sfere zakupok tovarov, rabot, uslug dlya obespecheniya gosudarstvennykh i munitsipalnykh nuzhd”» ot 12 dek. 2015 g. № 1367 [Decree of the Government of the Russian Federation "On the Procedure for Exercising Control Introduced by Part 5 of Article 99 of the Federal Law 'On the Contract System in the System of Procurement of Goods, Works and Services to Ensure State and Municipal Needs"” of December 12, 2015 no. 1367]. 
Sobranie zakonodatelstva RF, 2015, no. 52 (Part I), art. 7602 .

6. Arzumanova L.L., Boltinova O.V., Bubnova O.Yu. Pravovoe regulirovanie finansovogo kontrolya $v$ Rossiyskoy Federatsii: problemy i perspektivy: monografiya [Legal Regulation of Financial Control in the Russian Federation: Problems and Prospects Monograph]. Moscow, Norma Publ.; INFRA-M Publ., 2013. 384 p.

7. Prikaz FAS Rossii «Ob osushchestvlenii Federalnoy antimonopolnoy sluzhboy $i$ territorialnymi organami Federalnoy antimonopolnoy sluzhby polnomochiy po kontrolyu $v$ sfere zakupok tovarov, rabot, uslug dlya obespecheniya gosudarstvennykh i munitsipalnykh nuzhd $v$ svyazi s vstupleniem $v$ silu Federalnogo zakona ot 5 apr. 2013 g. № 44-FZ “O kontraktnoy sisteme $v$ sfere zakupok tovarov, rabot, uslug dlya obespecheniya gosudarstvennykh i munitsipalnykh nuzhd”" ot 11 fevr. 2014 g. № 75/14 [Russian FAS Order "On the Implementation by the Federal Antimonopoly Service and Territorial Agencies of the
Federal Antimonopoly Service of Control over the Procurement of Goods, Works and Services to Ensure State and Municipal Needs due to the Entry into Force of the Federal Law of April 5, 2013 no. 44-FL 'On Contract System in the Sphere of Procurement of Goods, Works, Services to Ensure State and Municipal Needs"" of February 11, 2014 no. 75/14]. Access from Reference Legal System "KonsultantPlyus".

8. Proshunin M.M. K voprosu o sootnoshenii finansovogo monitoringa i finansovogo kontrolya [On the Correlation Between Financial Monitoring and Financial Control]. Finansovoe pravo, 2010, no. 10, pp. 21-24.

9. Stroganov A.A. Goszakaz i kontrol za ego razmeshcheniem [The State Order and Control Over Its Placement]. Moscow, Yurisprudentsiya Publ., 2010. $208 \mathrm{p}$.

10. Khimicheva N.I., ed. Finansovoe pravo [Financial Law]. Moscow, Norma Publ.; INFRA-M Publ., 2012.752 p.

11. Gracheva E.I., ed. Finansovoe pravo [Financial Law]. Moscow, Prospekt Publ., 2015. 587 p.

\section{Information about the Author}

Imadi Ali Vugar oglu Huseynli, Postgraduate Student, Department of Civil and International Private Law (Basic Department of SSC RAS), Volgograd State University, Prosp. Universitetsky, 100, 400062 Volgograd, Russian Federation, gimchp@volsu.ru.

\section{Информация об авторе}

Имади Али Вугар оглы Гусейнли, аспирант кафедры гражданского и международного частного права (базовая кафедра ЮНЦ РАН), Волгоградский государственный университет, просп. Университетский, 100, 400062 г. Волгоград, Российская Федерация, gimchp@volsu.ru. 